\title{
Next generation exploration of UK future flood risks: High resolution climate, population and adaptation futures
}

\author{
Paul Sayers ${ }^{1}$, Horrrit $\mathrm{M}^{2}$, Kay $\mathrm{AL}^{3}$, Mauz J4, Carr $\mathrm{S}^{1}$ \\ ${ }^{1}$ Sayers and Partners, UK email: paul.sayers@sayersandpartners.co.uk \\ ${ }^{2}$ Horritt Consulting, UK \\ 3 UK Centre for Ecology and Hydrology. UKCEH \\ ${ }^{4} \mathrm{HRWallingford,} \mathrm{UK}$
}

\begin{abstract}
Under the Climate Change Act 2008 the UK Government is required to publish a Climate Change Risk Assessment (CCRA) every five years. In response to this requirement future flood risk across the UK is explored here under alternative climate change, population growth and adaptation policies through to the 2080s using an innovative emulation model (the Future Flood Explorer). The analysis highlights significant increases in flood risk with Expected Annual Damages rising from $£ 2$ bn today to $£ 2.7-3.0 \mathrm{bn}$ in the 2080s (depending upon associated population growth) given a $2 \mathrm{oC}$ rise in Global Mean Surface Temperature, and rising to $£ 3.5-3.9 \mathrm{bn}$ given a $4 \mathrm{oC}$ rise. The contribution of climate change, population and individual adaptation measures to future changes in flood risk are, for the first time, disaggregated, providing insight to the most significant drivers and important responses. The results highlight that to manage risk effectively under a 2 or $4 \mathrm{oC}$ future, an enhanced whole system approach to adaptation is needed with action required from a broad range of stakeholders, from national level down to individual households and businesses.
\end{abstract}

\section{Introduction}

The importance of understanding future flood risk in the context of a range of future scenarios was perhaps first formalized as part of the seminal Foresight Future Flooding Studies (Evans et al, 2004a\&b) and reinforced through the Climate Change Act 2008 that requires a UKwide Climate Change Risk Assessment (CCRA) to be undertaken every 5 years with future risks (across multiple sectors including flood risk) assessed under a range of climate, socio-economic and adaptation futures.

This paper explores the assessment of future flood risks undertaken as part of the $3^{\text {rd }}$ UK CCRA, based on the latest climate change projections (UK Climate Projections 2018; UKCP18), projections of population growth and alternative adaptation futures. The analysis is undertaken using an evolution of the innovative Future Flood Explorer (FFE), first developed to support the $2^{\text {nd }}$ UK CCRA (Sayers et al, 2015, 2016). The insights from the analysis, and an exploration of the associated benefits and costs of individual adaptation measures as part of portfolio of policy responses, are presented alongside the underpinning climate, socio-economic and adaptation assumptions.

\section{Overview of approach}

The FFE (Sayers et al, 2015, 2020) provides an assessment of future flood risk from fluvial, coastal, surface water and groundwater sources. The approach takes account of flood defences where they exist, future climate change, population growth and the influence of a portfolio of adaptation policy measures. The high computational efficiency of the FFE allows multiple future scenarios to be explored across the UK. Here, this includes two climate change scenarios, representing a $2^{\circ} \mathrm{C}$ and $4^{\circ} \mathrm{C}$ rise in Global Mean Surface Temperature (GMST) by 2100; none, low and high population projections; and a widerange of adaptation measures as part of three coherent adaptation portfolios - Figure 1. The drivers of changed are detailed in turn below. 


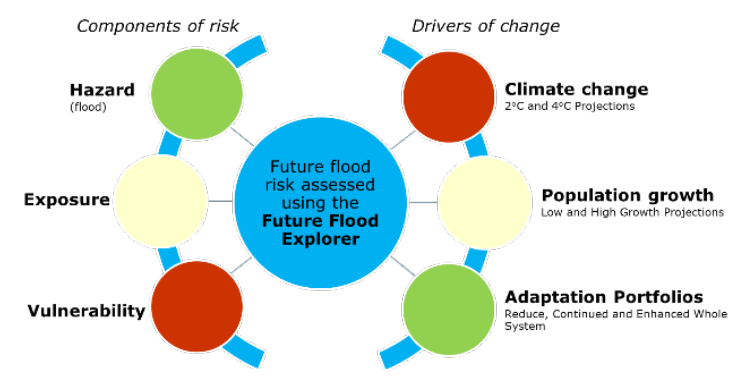

Figure 1. Overview of the structure of the analysis.

\subsection{Influence of climate change on flood hazards}

To provide a coherent understanding of the influence of climate change on the various flood sources the climate scenarios are framed using an increase in Global-MeanSurface-Temperature (GMST). Two scenarios are considered; a $2^{\circ} \mathrm{C}$ and $4^{\circ} \mathrm{C}$ rise in GMST by 2100 (from pre-industrial times). This framing, although widely used (e.g. Sayers et al, 2015, Koks et al, 2020), does however present two difficulties.

1. There is no unique pathway to 2 or $4^{\circ} \mathrm{C}$ : Across the standard Representative Concentration Pathways (RCPs, van Vuuren et al., 2011) many of the ensemble members from the UKCP18 Probabilistic Projections (Lowe et al, 2018) show an increase in GMST of $2^{\circ}$ or $4^{\circ} \mathrm{C}$ by 2100 . To avoid the overhead of modelling all of these futures, a mean of those members that project a rise of $2^{\circ} \mathrm{C}$ and $4^{\circ} \mathrm{C}$ (within a tolerance of $+/-0.1$ between 2090-2100 from a pre-industrial baseline) are used to construct two profiles of the rise in GMST with time - Figure 2 .

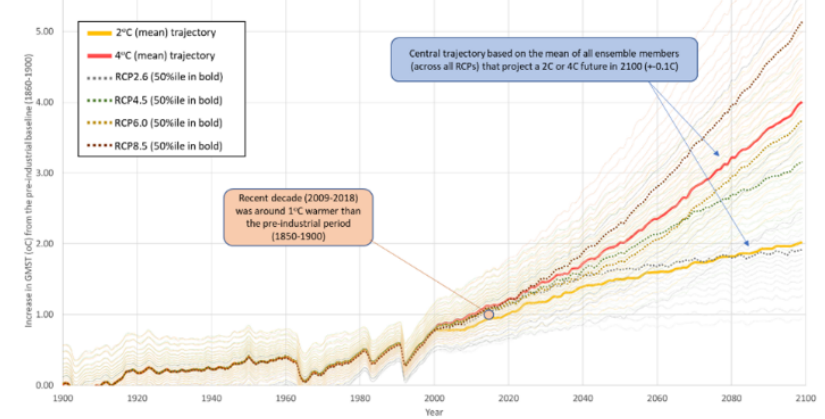

Source from Sayers et al, 2020 using data from UKCP18 probabilistic projections

Figure 2. Rise in GMST to 2100

2. Not all sources respond only to temperature change: The approach to determining the influence of climate change on each flood source necessarily varies within the analysis to reflect the available underlying data from UKCP18 and constraints of analysis resource effort:

High-resolution changes in peak fluvial flows: All UKCP18 Probabilistic Projections that reach a 2 or $4^{\circ} \mathrm{C}$ rise in GMST in or before 2100 (from a pre-industrial baseline) are used in assessing the change in fluvial flows and associated extreme water levels on a $1 \mathrm{~km}$ grid across the UK.
High-resolution changes in sea levels and coastal wave driven overtopping: The UKCP18 sea level projections used are based on the climate model simulations of the Coupled Model Inter-comparison Project Phase 5 (CMIP5, Taylor et al., 2012) and additional analysis by Palmer et al., (2018) that in-combination include the influence of oceanographic processes, gravitational and other adjustments due to ice melt and changes to terrestrial water storage as well as the elastic response of the land to the last de-glaciation to provide relative sea level rise estimates. rSLR estimates are then used Further processing is then used to assess the change in the standard of protection afforded by coastal defences using approach set out by Gouldby et al., 2017.

Changes in pluvial flooding driven by short duration rainfall intensity (<6hours): Climate models are relatively poor at simulating short duration precipitation extremes (e.g. Kendon et al., 2014). This is primarily due to the relatively coarse resolution of climate models to date and their inability to capture important processes, such as convection. The development of finer-grid models remains in its infancy and data from the Met Office UKCP $2.2 \mathrm{~km}$ climate model (Kendon et al., 2019) is yet to be fully mined. A combination of evidence is therefore used here to estimate the change in short duration rainfall intensity, including the Environment Agency guidance on climate allowances (Environment Agency, 2016a\&b).

\subsection{Influence of population growth}

Analysis by Cambridge Econometrics (2019) is used to provide two projections of population growth:

- High growth: Based on the ONS 'young age structure' variant of its principal population projection, the high growth projection assumes fertility rates and net migration are higher than in the central case while life expectancy is lower. The UK population grows to $\sim 88$ million in 2100 , an increase of almost 27 million from 2016. The population has a younger age structure than in the central projection, with $59 \%$ of the population of working age ( $4 \%$ more than the central projection). The proportion of dependents aged between $0-15$ is also slightly higher in the high scenario, reflecting higher birth rates.

- Low growth: Based on the ONS 'old age structure' variant of its principal population projection, the low growth projection assumes fertility rates and net migration are lower than in the central case while life expectancy is higher. The UK population reaches to $\sim 68$ million in 2100, an increase of just 1 million from 2016 and leads to an older age structure (with over $65 \mathrm{~s}$ accounting for $36 \%$ of the population, compared to $29 \%$ in the central scenario).

These changes (illustrated in Figure 3) translate into increased properties and population on the floodplain through the action of the spatial planning adaptation. 

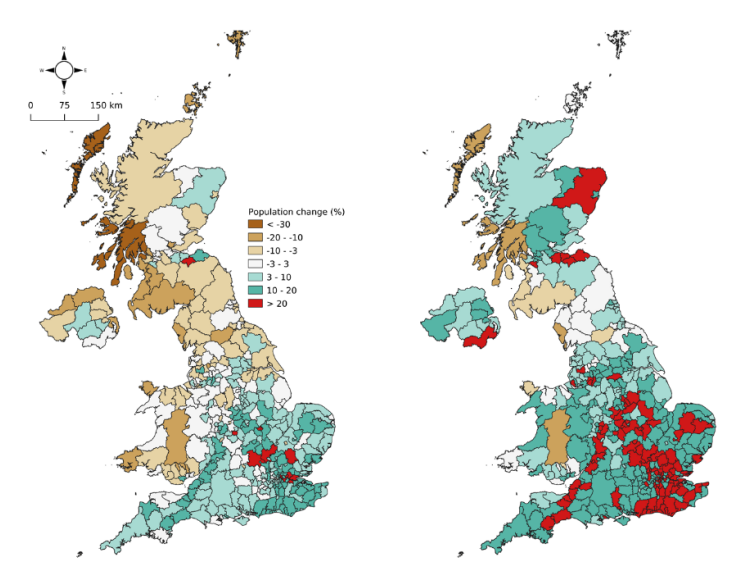

Source Left: low population growth. Right: high population growth. Data source: Cambridge Econometrics, 2019

Figure 3. Population projection by UK Local Authority - 2080s

\subsection{Influence of adaptation}

It is widely recognised that flood risk is best managed through a portfolio of measures implemented through a continuous process of adjustment (e.g. Evans et al 2004a\&b, Sayers et al., 2013,2014). The portfolio approach is also reflected here with nine individual Adaptation Measures (AMs) combined into three alternative Adaptation Portfolios (AP) that represent different levels of policy ambition:

- No additional action: Leading to Reduced Whole System (RWS) Adaptation: In the context of flooding, this does not mean taking no further action to maintain or improve flood defences for example, or assume that existing defence standards are maintained at presentday levels in all locations in all climate futures. Instead, the 'no additional action' baseline assumes adaptation to flood risk continues but investment in conventional defences fails to keep pace with climate change; there is limited take up of catchment-based or urban run-off measures; pressure for development and economic growth lead to continued new development on the floodplain; receptor (property) level flood resilience (PFR) continues to experience limited takeup amongst existing properties. There are several plausible reasons that may lead to such a situation. Other threats may become increasingly dominant in public funded priorities (translating to a reduction in the willingness to pay for flood risk management) or our collective capacity to promote and deliver flood risk management may wane as political and social capital is directed towards other priority issues.

- Current objectives: Leading to a continuation of Current Levels of Adaptation (CLA): The 'current objectives' policy response used here assumes flood risk management policies continue to be implemented as in the recent past whilst taking on board anticipated changes that are likely to result from recent changes in policy, such as the 25 Year Environment Plan and the National Planning Policy Framework in England, continued evolution of TAN15 in Wales, and National Planning Framework No. 4 in Scotland. These and similar documents are likely to encourage greater uptake of Natural Flood Management (NFM) and property flood resilience (PFR) measures than achieved in recent years and continue to encourage greater investment in FRM.

- Current Objectives+: Leading to an Enhanced Whole System adaptation (EWS): The 'current objectives ${ }^{+}$' scenario goes beyond the current implementation of policy to represent an 'Enhanced Whole System' (EWS) approach to adaptation. For example, investment in flood defence increases (including in more socially disadvantaged neighbourhoods) and land use planning policy is more successful in restricting development in the floodplain than currently achieved or anticipated. Awareness raising and a strengthening of building regulations and planning controls encourage greater receptor level resilience. Forecasting and warning systems develop with increased levels of sophistication, targeting those at risk more accurately than has been possible to date. Opportunities for more integrated planning and implementation are sought (e.g. Ministry of Housing, Communities and Local Government, MHCLG, 2018 and 2019, Welsh Government, WG, 2018) and, together with increasing momentum towards a 'net zero' emissions future, nature-based solutions are increasingly promoted and greater resilience delivered.

\section{Projected future changes in flood risk}

The analysis finds that assuming a continuation of Current Levels of Adaptation, Expected Annual Damages (EAD, including direct economic damage to residential and nonresidential properties and associated indirect damages) are set to increase from present-day levels. Under a $2^{\circ} \mathrm{C}$ future EAD rises from $£ 2$ bn today to $£ 2.7-3$.0bn in the 2080 s (depending upon associated population growth). Under a $4^{\circ} \mathrm{C}$ future risks rise to between $£ 3.5-3.9 \mathrm{bn}$.

It also finds that fluvial flood risk is dominant today when looking at the UK as a whole, and remains so in the future; rising from an EAD of $\sim £ 1$.1bn today to between $\sim £ 1.2$ bn $\left(2^{\circ} \mathrm{C}\right.$ low population growth) and $\sim £ 1.6$ bn $\left(4^{\circ} \mathrm{C}\right.$ high population growth) by the 2080 s assuming a continuation of Current Levels of Adaptation. The increase in fluvial flood risk is, however, proportionally less than for either coastal or surface water flooding. Surface water and coastal risks more than double under a $4^{\circ} \mathrm{C}$ high population growth future (surface water risks rising from $\sim £ 0.6$ bn to $\sim £ 1.2$ bn by the $2080 \mathrm{~s}$ and coastal risks increasing from $\sim £ 0.4$ bn to $\sim £ 1$.0bn).

The most important driver of these changes is climate change. Climate change is the dominant influence in driving up future risk (increasing Expected Annual Damages EAD - direct and indirect - by $£ 4.2$ bn under a $2^{\circ} \mathrm{C}$ future and $£ 6.9$ bn under a $4^{\circ} \mathrm{C}$ future in the absence of any adaptation). The influence of climate change is greatest at the coast; especially when the rise in GMST exceeds $2^{\circ} \mathrm{C}$, with EAD rising by a further $70 \%$ under a $4^{\circ} \mathrm{C}$ rise in GMST compared to $2^{\circ} \mathrm{C}$. For comparison, the risks associated with all other flood sources increase by 
$\sim 20 \%$ between a 2 and $4^{\circ} \mathrm{C}$ future. The influence of population varies with the projection of growth. Assuming low population growth the additional impact on risk is limited (although not insignificant, adding $£ 364 \mathrm{~m}$ to EAD), whereas high population growth has a much greater influence (adding $\sim £ 2.4 \mathrm{bn}$ to the EAD assuming a $4^{\circ} \mathrm{C}$ rise in GMST). By the 2080 s the combination of a $4^{\circ} \mathrm{C}$ climate change and high population growth drives an increase of $\sim £ 9.2$ bn EAD in the absence of adaptation. The future is therefore bleak in the absence of adaptation and mitigation.

All three adaptation portfolios limit this increase. A continuation of Current Levels of Adaptation offsets $\sim £ 7.4$ bn of EADin the 2080 s (under a $4^{\circ} \mathrm{C}$ future with high population growth) resulting in a net increase in risk of $\sim £ 1.8 \mathrm{bn}$. An Enhanced Whole System (EWS) approach to adaptation offsets $\sim £ 8.2 \mathrm{bn}$ of EAD (total) in the same scenario; limiting the net increase in risk to $\sim £ 1$.1bn. A Reduced Whole System approach offsets much less ( $£ 6.4 \mathrm{bn})$; consequently, the net increase in risk is much greater $(\sim £ 2.8 \mathrm{bn})$. Figure 4 illustrates these disaggregated risks.

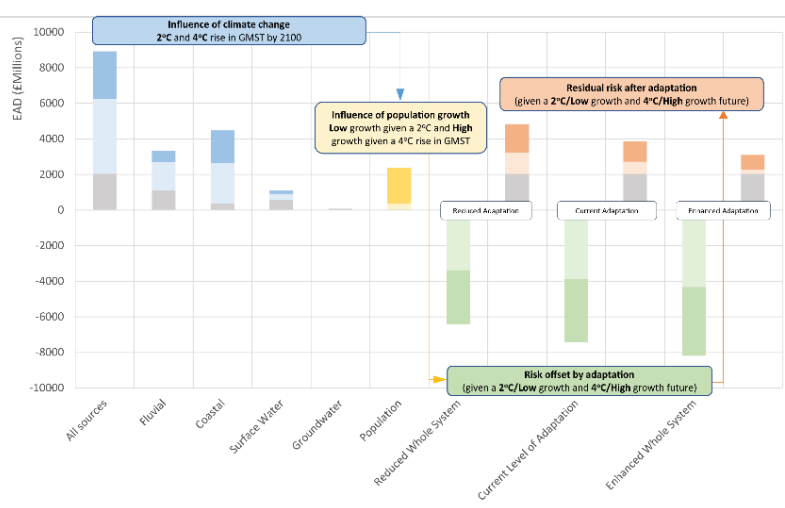

Positive bars show present-day and increases in present-day risks as a result of climate change or population growth by the 2080s. Negative bars show how the EAD for $a 4^{\circ} \mathrm{C}$, high population, scenario can be offset by applying the three adaptation portfolios. Grey shading: Present-day risk. Lighter non-grey shading: Additional risk in the 2080s compared to present-day under a $2^{\circ} \mathrm{C}$ future; Darker non-grey shading: Additional risk under $a 4^{\circ} \mathrm{C}$ future compared to a $2^{\circ} \mathrm{C}$ future.

Figure 4 A disaggregation of the drivers of changes in risk by 2080s using the Future Flood Explorer - Expected Annual Damage (total)

Climate change also impacts the standard of protection afforded by flood defences. In the absence of any further adaptation the reduction in the standard of protection provided is significant. This reduction is most marked at the coast (see Figure 5). The impact of climate change on fluvial defences is more mixed with some areas experiencing a small increase in their effective standard of protection as peak flood flows reduce (reflecting the complex spatial pattern of future changes in peaks flows).

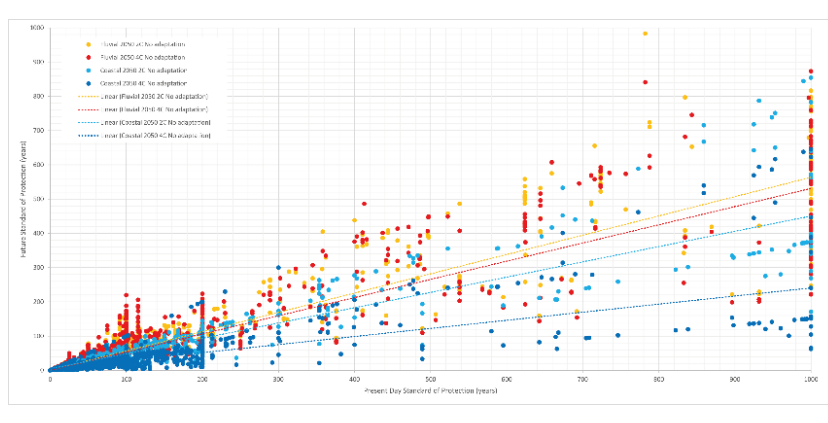

$x$-axis represents the present-day representative standard of protection (for each fluvial and coastal neighbourhood). $y$-axis presents the future standard by the 2050s under a 2 and $4^{\circ} \mathrm{C}$ climate future.

Figure 5 Impact of climate change on defence standards: 2050s assuming no adaptation

Catchment (natural) management provides a meaningful contribution to reducing the impact of climate change on conventional defence standards and reducing risk by limiting the the impact of more frequent floods on expected annual damages. The analysis suggests that investment in catchment management provides significant returns when combined with conventional flood defences (as here) across the UK. with a Benefit to Cost Ratio (BCR) of greater than $\sim 20$ across all portfolios. This reflects the comparatively low cost and an ability to meaningfully contribute to the management of more frequently occurring flood events that often drive EAD.

The analysis also provides a perspective on how risks are changing for the most socially vulnerable. In many rural towns and villages and smaller urban cities and towns the most socially vulnerable ${ }^{a}$ are, on average, exposed to greater flood risk. For example, in some rural setting the present-day EAD is on average $£ 150$ per person (for those living in flood prone areas) but almost double this ( $£ 280$ per person) in the most socially vulnerable neighbourhoods (on average). In the future the most socially vulnerable, particularly in urban cities and towns, coastal areas and post-industrial cities experience disproportionate increases in risk, with the EAD per person increasing by a factor of 2.5 on average but by 2.8 in the most socially vulnerable neighbourhoods.

\section{Conclusions}

The innovative analysis provided by the Future Flood Explorer enables a consistent UK-wide assessment of future flood risk taking account of four sources of flooding, population growth and adaptation. The FFE has been shown to be a practical and credible approach that is fast to run enabling multiple futures to be explored. The analysis present here (using the latest climate projections form UCP18, population projections from Cambridge Econometrics and the detailed consideration of alternative adaptation policy portfolios) highlights:

\footnotetext{
${ }^{\text {a }}$ As defined by the $20 \%$ most socially vulnerable neighbourhoods according to the Neighbourhood Flood Vulnerability Index, NFVI, Sayers et al, 2016 and available via Oasis platform.
} 
- Sources of flood risk: Fluvial flooding contributes the greatest to economic damages now and in the future but the relative contribution of both surface water and coastal flooding increases.

- Changing standards of flood defences: The reduction in the standard of protection afford by defences, in the absence of adaptation, is most marked at the coast. In fluvial settings most defences experience a reduction in standard but with significant spatial variation reflecting the complex spatial pattern of future changes in peaks flows.

- Risk for agriculture: The changing nature of habitats and the impact of climate change on agricultural damage responds to multiple variables not explicitly considered here (changes in the seasonality, salinity, chosen crops, local land management practice etc.). There is however an increase in exposure of agricultural land (Best and Most Versatile land) to frequent flooding (at least 1 in 30 years ). The largest increases are projected in the agricultural heartlands of Lancashire and Northamptonshire as well as Bedfordshire, Cambridgeshire and Yorkshire. Flooding may also impact agricultural land in more marginal locations that have little (or no) Best and Most Versatile land. The impact on these more marginal lands (and associated activities and communities) is not considered here.

- Systemic social flood disadvantage: The most socially vulnerable experience the greatest level of disadvantage across the $\mathrm{UK},-$ this is case today and in the future.

- Spatial planning approaches: The only adaptation response that acts to directly mitigate the influence of population growth is spatial planning; but spatial planning is always context specific. Many Local Authorities cannot avoid development in the floodplain whilst others have much more flexibility. The national planning framework needs to recognise this reality more directly and help locations that must build on the flood plain to do so in the context of a long-term plan to reduce risk and maintain safety. In some areas this may be by enforcing property level measures (for example in areas prone to fluvial flooding) but in coastal areas this is likely to mean a commitment to maintain appropriate long-term protection (together with an acceleration in cost that is likely to follow) or implement managed retreat (an adaptation option not explicitly considered here). Indecision today has the potential to lock-in risk for future generations.

- Coastal and estuarine areas: Many estuary and coastal urban areas are unable to avoid floodplain development. Coupled with relative sea level rise (rSLR) this leads to a major increase in coastal flood risk (the fastest growing of all hazards).

- Catchment management provides a meaningful contribution to economic risk reduction: The analysis suggests significant benefit to cost ratios based on economic benefits alone, noting that catchment management approaches also offer a wide range of co-benefits not considered here. The knowledge on the long-term performance of catchment management is however limited compared to the performance of conventional flood defences or planning measures. This lack of comparable knowledge should not be a barrier to appropriate use as a legitimate component of a portfolio response given the wide range of associated benefits but should be addressed.

- Going beyond Current Objectives+: Under all adaptation portfolios considered here, risks rise under a 2 and $4^{\circ} \mathrm{C}$ climate future. To maintain present-day risk levels constant to the end of the century continued innovation in adaptation approaches will be required. This may include, for example, greater effort towards making space for coastal and river dynamics within local and large-scale planning and development choices (including coastal realignment) as well as more integrated actions to address the increase in surface water flood risk.

\section{Acknowledgements}

The authors are grateful to the UK Climate Change Committee for the opportunity to work on this interesting issue. Paul Sayers' time for leading this paper is supported under the UK Climate Resilience Programme and the University of East Anglian, Tyndall Centre.

\section{References}

1. Cambridge econometrics (2019). A consistent set of socioeconomic dimensions for the CCRA3 Evidence Report research projects.

2. Environment Agency (2016a) Adapting to Climate Change: Advice for Flood and Coastal Erosion Risk Management Authorities. Environment Agency, March 2016, 23. Available at: www. gov. uk/government/publications/adapting-toclimate-changefor-risk-management-authorities

3. Environment Agency (2016b) Flood risk assessments: Climate change allowances. Available at: www. gov. uk/guidance/flood-risk-assessments-climate-changeallowances

4. Evans, E.P, Ashley, R, Hall, J.W, Penning-Rowsell, E.P, Saul, A, Sayers, P.B, Thorne, C.R, and Watkinson, A. (2004a). Foresight Future Flooding, Scientific Summary: Volume 2: Managing future risks. Published by the Office of Science and Technology, London.

5. Evans, E.P, Ashley, R, Hall, J.W, Penning-Rowsell, E.P, Saul, A, Sayers, P.B, Thorne, C.R, and Watkinson, A. (2004b). Foresight Future Flooding, Scientific Summary: Volume 1: Future risks and their drivers. Office of Science and Technology, London.

6. Gouldby, B. P., Wyncoll, D., Panzeri, M., Franklin, M., Hunt, T., Hames, D., Tozer, N. P., Hawkes, P. J., Dornbusch, U. and Pullen, T. A. (2017) Multivariate extreme value modelling of sea conditions around the coast of England. Proceedings of the Institution of Civil Engineers - Maritime Engineering, 170 (1). pp. 3-20.

7. Kendon, M., McCarthy, M., Jevrejeva, S., Matthews, A. and Legg, T., (2019). State of the UK climate 2018. International Journal of Climatology, 39, pp.1-55. 
8. Kendon, E. J., Roberts, N.M., Fowler, H. J., Roberts, M. J., Chan, S. C. and Senior, C.A. (2014) Heavier summer downpours with climate change revealed by weather forecast resolution model. Nature Climate Change, 4, 570576, doi:10. 1038/nclimate2258.

9. Koks, E, Sayers P et al, (2020) Development of storylines for exploring future coastal climate risk. A report of the EC H2020 RECIEPT Project

10. Lowe JA, Bernie D, Bett P, Bricheno L, Brown S, Calvert D, Clark R, Eagle K, Edwards T, Fosser G, Fung F. UKCP18 science overview report. Exeter, UK: Met Office Hadley Centre. 2018.

11. Ministry of Housing, Communities and Local Government (2019). National Planning Policy Framework. Ministry of Housing, Communities \& Local Government https://www. gov. uk/government/publications/national-planning-policyframework-2

12. Ministry of Housing, Communities and Local Government (2018). A review of the application and effectiveness of planning policy for Sustainable Drainage Systems (SuDS). London

13. Palmer, M. D., Howard, T., Tinker, J., Lowe, J. A., Bricheno, L., Calvert, D., Edwards, T., Gregory, J., Harris, G., Krijnen, J. \& Roberts, C. (2018) UKCP18 Marine Report.

14. Sayers, PB., Horritt, M, Carr, S, Kay, A, and Mauz, J (2020) Third UK Climate Change Risk Assessment (CCRA3): Future flood risk. Research undertaken by Sayers and Partners for the Committee on Climate Change. Published by Committee on Climate Change, London.

15. Sayers et al (2016). The analysis of future flood risk in the UK using the Future Flood Explorer (FFE). Proceedings of Floodrisk2016. Paul Sayers, Matt Horritt, Edmund PenningRowsell, Andrew McKenzie and David Thompson. E3S Web Conf., 7 (2016) 21005 DOI: http://dx.doi.org/10.1051/e3sconf/20160721005

16. Sayers, P.B., Horritt, M. S., Penning-Rowsell, E., and Mckenzie, A. (2015). Climate Change Risk Assessment 2017: Projections of future flood risk in the UK. Pages 125. Sayers and Partners LLP report for the Committee on Climate Change.

17. Sayers P B, Galloway Gerry, Penning-Rowsell Edmund, Shen F, Wen K, Chen Y, Le Quesne T (2014). Strategic flood management: ten 'golden rules' to guide a sound approach. Journal: International Journal of River Basin Management. DOI: 10.1080/15715124.2014.902378

18. Sayers P B, Galloway Gerry, Penning-Rowsell Edmund, Shen F, Wen K, Chen Y, Le Quesne T (2013). Flood Risk Management : A strategic approach. Published in English by UNESCO, Paris in May 2013 (ISBN 978-92-3-0011598) and in Chinese by Water Publishing in October 2012 (ISBN:978-7-5170-0201-7). Published in association with WWF, the General Institute of Water Design and Planning, Beijing (GIWP) China and Asian Development Bank (ADB).

19. Taylor, K.E., Stouffer, R.J. and Meehl, G.A., 2012. An overview of CMIP5 and the experiment design. Bulletin of the American meteorological Society, 93(4), pp.485-498.

20. van Vuuren et. al (2011). The representative concentration pathways: an overview. Published in Climatic Change (2011) 109:5-31, DOI 10. 1007/s10584-011-0148-Z

21. Welsh Government (2018). Planning Policy Wales. Edition 10 | December 2018 